\title{
Pengaruh Variasi Temperatur Terhadap Kuantitas Char Hasil Pirolisis Serbuk Kayu Mahoni (Switenia Macrophylla) Pada Rotary Kiln
}

\author{
Ikhwanul Qiram,Denny Widhiyanuriyawan, Widya Wijayanti \\ Jurusan Teknik Mesin Universitas Brawijaya Indonesia \\ Jalan M.T. Haryono, 167 - Malang (65145) - Indonesia \\ E-mail: ikhwanulqiram@gmail.com
}

\begin{abstract}
Pirolysis is thermochemical decomposition process of biomass into useful product. One kind of method that can be used is a Rotary Kiln pirolyzer which is consist a heating cylinder that rotates with a certain rotation speed. This research is aimed to get the effect of temperature due to Char product quantity of switenia macrophylla Rotary Kiln pirolysis. The research has done by pirolysis experiment with 200 gram of switenia macrophylla in dust form. Temperature was varied $250^{\circ} \mathrm{C}$, $350^{\circ} \mathrm{C}, 450^{\circ} \mathrm{C}, 500^{\circ} \mathrm{C}$, and $600^{\circ} \mathrm{C}$. The heating temperature was provided by eletric heater with control system. Temperatur was measured with $K$ type thermocouple. The heating process has taken for 180 minutes using stopwatch. The measurement has done for biomass and Char volume using measuring cup. Mass was measured by using mass scale. Low heating value was measured by using bomb calorimeter. The result show that the temperature has effect due to Char product of switenia macrophylla Rotary Kiln pirolysis. The loss of Char mass is tend to increase due to temperature increases. Low heating value and Char porosity is tend to increase due to mass loss percentage increases. Shrinking factor and percentage of yield energy is tend to decrease due to mass loss percentage increasing.
\end{abstract}

Keywords : pirolysis, Rotary Kiln, Char, temperature

\section{PENDAHULUAN}

Semakin bertambahnya populasi
manusia dan meningkatnya laju industrialisasi di berbagai negara di dunia menyebabkan tingkat pemakaian bahan bakar terutama bahan bakar fosil semakin meningkat. Untuk itu perlu dilakukan upayaupaya untuk meningkatkan per tumbuhan energi baru dan terbarukan khususnya dari biomassa padat dalam memenuhi kebutuhan energi yang selalu bertambah seiring bertambahnya jumlah penduduk. Untuk dapat mengatasinya salah satu teknologi yang dapat digunakan adalah teknologi pirolisis.

Pirolisis yang juga disebut termolisis akan mendekomposisi kimia bahan organik (biomassa) melalui proses pemanasan tanpa atau sedikit $\mathrm{O}_{2}$ atau reagen lainnya, dimana material mentah akan mengalami pemecahan struktur kimia menjadi fase gas. Teknik ini adalah cara untuk memperoleh hasil hidrokarbon yang merupakan dasar bahan bakar. Teknologi pirolisis dikembangkan dengan variasi metode untuk teknologi bersih dan memiliki aspek pemanfaatan sumber daya alam [1]. Dalam proses pirolisis penggunaan energi sangat besar, dimana energi tersebut digunakan untuk memecah unsur kimia pada bahan pirolisis menjadi moleku-molekul kecil yang ringkas dan menjadi fase gas. Dengan adanya kelemahan tersebut maka perlu dilakukan optimasi penggunaan energi, untuk kepentingan ini, optimasi meliputi laju pemanasan, ukuran partikel bahan, tekanan dan juga identifikasi pirolisis utama dan pirolisis sekunder dalam proses yang berlangsung serta merancang desain reaktor [2].Laju pemanasan berpengaruh terhadap kurva perubahan massa, laju dekomposisi maksimum. Laju pemanasan dihitung dengan persamaan sebagai berikut:

$\frac{\Delta T}{\Delta t}=\frac{T_{1}-T_{2}}{\Delta t}$ 
Dimana:

$\mathrm{T}_{1}=$ Temperatur akhir $\left({ }^{\circ} \mathrm{C}\right)$

$\mathrm{T}_{2}=$ Temperatur awal $\left({ }^{\circ} \mathrm{C}\right)$

Selanjutnya dihitung nilai rata-rata laju pemanasan sehingga didapat nilai rata-rata laju pemanasan dalam penelitian ini sebesar $8,60^{\circ} \mathrm{C} /$ menit atau $0,14^{\circ} \mathrm{C} / \mathrm{dt}$.

Salah satu biomassa yang mudah kita temui adalah limbah dari serbuk mahoni yang berasal dari industri pengolahan kayu. Jenis kayu mahoni banyak ditanam di hutan-hutan Indonesia [3]. Limbah yang terjadi dari pohon yang ditebang, yaitu berupa kayu sampai dengan diameter $15 \mathrm{~cm}$ adalah sebesar $57 \%$, sehingga yang dapat dimanfaatkan dari pohon yang ditebang tersebut hanya sebesar $43 \%$. Volume bebas dahan sebesar 21,34 $\mathrm{m}^{3}$ akan dihasilkan kayu bulat sebanyak $73 \%$, sisanya $27 \%$ merupakan limbah dan $71,5 \%$ dari limbah tersebut akan ditinggalkan di petak tebang [4].

Mahoni merupakan salah satu jenis kayu yang banyak digunakan dalam industri pengolahan kayu di Indonesia, pada saat ini terdapat 19 buah industri pembuatan papan partikel di Indonesia. Industri ini memanfaatkan limbah kayu dari industri pengolahan kayu sebagai bahan bakunya [5]. Produksi total kayu gergajian Indonesia mencapai 2.6 juta $\mathrm{m}^{3}$ per tahun. Dengan asumsi bahwa jumlah limbah yang terbentuk $54.24 \%$ dari produksi total maka dihasilkan limbah penggergajian sebanyak 1.4 juta $\mathrm{m}^{3}$ per tahun [6]. Hal ini turut mendorong untuk meningkatkan nilai tambah dari produksi kayu olahan dari sisi limbah serbuk gergaji yang dihasilkan menjadi sumber energi.

Salah satu parameter yang mempengaruhi kualitas produk Char hasil pirolisis adalah temperatur. Jika temperatur dinaikkan, maka molekul pada biomassa memiliki tingkat energi yang meningkat [7]. Dengan meningkatnya temperatur pirolisis maka massa dan volume Char yang terbentuk akan semakin kecil pada setiap peningkatan variasi temperatur, sedangkan nilai kalornya akan semakin meningkat [1].

Pada penelitian ini jenis teknologi yang digunakan adalah pirolisis Rotary Kiln. Dimana Rotary Kiln merupakan dapur horisontal tubular dengan biomassa yang digerakkan dengan laju tertentu sepanjang dapur. Dalam segi mekanisme pirolisis, dilakukan penelitian dengan variasi kecepatan putar, temperatur peleburan dan ukuran butir konsentrat zirkon menggunakan Rotary Kiln [8]. Gerak partikel biomassa dalam Rotary Kiln terkonsentrasi pada dinding kiln dalam lapisan pasif (passive layer). Lapisan ini akan mencapai bagian permukaan dimana lapisan bergeser ke bawah dalam lapisan aktif (active layer). Mengacu pada sebuah partikel, proses berulang ini menyebabkan partikel bergerak kea rah aksial setiap kali bergerah ke arah lapisan aktif. Proses ini menjadi dasar bagi pemodelan gerak partikel di Rotary Kiln pada arah aksial. Model ini dapat menjadi prediksi lapisan pengisian (area bagian pada arah penampang lintang radial) sepanjang silinder Rotary Kiln sebagai sebuah fungsi laju masuknya bahan biomassa.

Pada komponen serbuk kayu mahoni, zat-zat yang dapat didekomposisi yaitu Cellulose, Hemicellulose dan Lignin, dari zatzat itu akan mengalami dekomposisi sendirisendiri dalam proses pirolisis. Partikel-partikel biomassa mengalami perubahan volume dan perubahan massa. Besar prosentase perubahan massa dihitung dengan persamaan [9].

$$
M L=\frac{M_{i}-M_{f}}{M_{i}} \times 100
$$

Dimana:

$$
\begin{aligned}
& M_{f}=\text { massa akhir }(\mathrm{kg}) \\
& M_{i}=\text { massa awal }(k g)
\end{aligned}
$$

Pemberian perlakuan putaran pada tungku pirolisis diharapkan akan memberikan dampak pada partikel biomassa kayu mahoni. Dimana tumbukan antar partikel terjadi pada transfer momentum yang diakibatkan oleh putaran tungku, yang selanjutnya dapat menyebabkan partikel biomassa dengan massa tertentu bergerak dengan kecepatan tertentu [10]. Hal ini secara keseluruhan diduga akan memberikan pengaruh terhadap dekomposisi biomassa serta nilai produk Char hasil pirolisis serbuk kayu mahoni.

\section{METODE PENELITIAN}

Pada penelitian ini terdapat 3 variabel 
yang digunakan, yaitu variabel bebas, terikat, dan terkontrol. Variabel bebas adalah temperatur pemanasan pada saat proses pirolisis. Variabel terikatnya adalah massa Char setelah pirolisis, volume Char setelah pirolisis, dan nilai kalor Char. Dan variabel terkontrolnya adalah laju pemanasan 8,6 ${ }^{\circ} \mathrm{C} /$ menit, Putaran tungku $10 \mathrm{Rpm}$ dan Waktu pirolisis selama 180 menit.

Bahan yang digunakan adalah serbuk kayu mahoni dari wilayah selatan Kabupaten Malang, Jawa Timur. Instalasi pirolisis Rotary Kiln berfungsi untuk mendekomposisi bahan baku serbuk kayu mahoni.

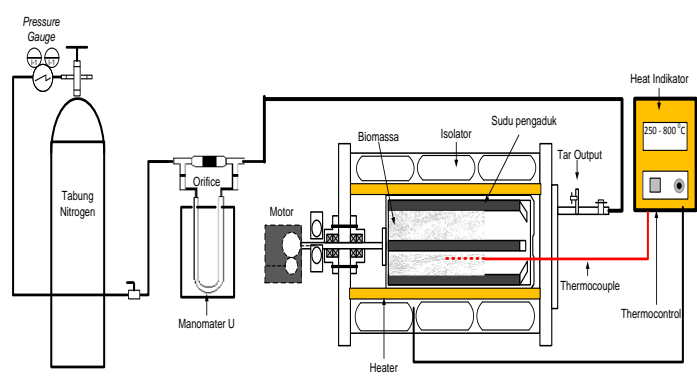

Gambar 1. Instalasi Penelitian

Persiapan yang dilakukan pertama kalinya adalah menyaring serbuk kayu mahoni. Kotoran-kotoran serbuk kayu mahoni dibersihkan dengan cara disaring. selain itu pengayakan juga dilakukan dengan tujuan untuk menyeragamkan ukuran serbuk kayu mahoni (biomassa) dengan range 0,5 - 1 $\mathrm{mm}$. Selanjutnya mengeringkan serbuk kayu mahoni untuk mengurangi kadar air sampai $<2 \%$ dengan oven pemanas pada temperatur $110-125^{\circ} \mathrm{C}$ selama $2-3$ jam. Selanjutnya dilakukan penimbangan sampel sebesar 200 gr untuk dipirolisis.

Setelah langkah persiapan awal dilakukan, Spesimen uji dimasukkan ke dalam pyrolyzer dan pyrolyzer ditutup. selanjutnya buka katup untuk mengalirkan $\mathrm{N}_{2}$ ke ruang pemanas pyrolyzer sampai kadar $\mathrm{O}_{2}<2,1 \%$ dari volume ruang pemanas dan buka juga katup buang pada pyrolizer supaya $\mathrm{O}_{2}$ dapat terdorong keluar akibat dorongan dari $\mathrm{N}_{2}$ yang memenuhi tabung. Dengan rentang 1 menit dengan flow rate 3 liter per menit. Thermocontroller diatur untuk variasi pertama yaitu $250{ }^{\circ} \mathrm{C}$, Motor penggerak dapur dihidupkan dan diatur kecepatan putarnya dengan kecepatan atur
10 Rpm. Lakukan proses pirolisis Rotary Kiln sampai batas temperatur yang ditentukan, setelah itu tahan beberapa menit atau sampai kenaikan volume tidak ada perubahan.

Produk Char serbuk kayu mahoni yang telah dipirolisis selanjutnya diukur massa dan volume akhir produk Char hasil pirolisis. Ulangi prosedur pirolisis dengan variasi temperatur $350^{\circ} \mathrm{C}, 450^{\circ} \mathrm{C}, 500^{\circ} \mathrm{C}$, dan $600^{\circ} \mathrm{C}$

\section{PEMBAHASAN}

\section{Laju Pemanasan}

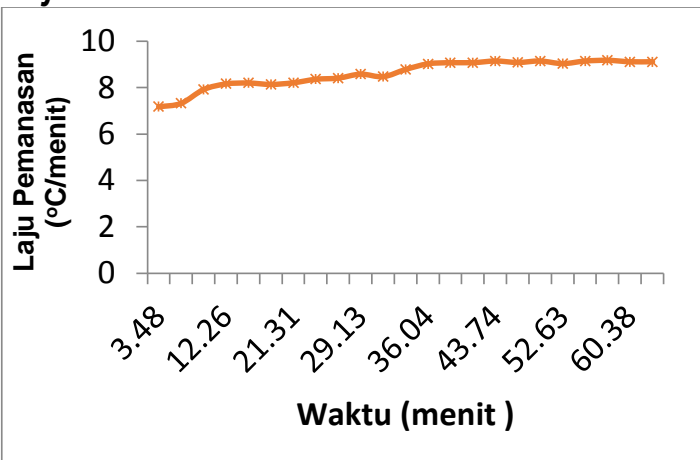

Gambar 2. Grafik Laju Pemanasan

Gambar 2 menunjukkan laju pemanasan menunjukkan kenaikan suhu secara linier, laju pemanasan cenderung sesuai dengan kenaikan waktu pengukuran. Hal ini sesuai dengan pertambahan temperatur dari suhu awal sebesar $25^{\circ} \mathrm{C}$ menjadi $50^{\circ} \mathrm{C}$ dan selanjutnya naik secara bertahap hingga mencapai suhu $600^{\circ} \mathrm{C}$.

Produk utama dari slow pirolisis adalah Char (arang). Pada pirolisis Rotary Kiln ini laju pemanasan berjalan lambat, temperatur kecil, dan waktu pemanasan yang lama. Dimana dalam penelitian ini laju pemanasan yang digunakan adalah $0,14^{\circ} \mathrm{C} /$ detik.

\section{Temperatur Dinding dan Biomassa}

Profil temperatur merupakan aspek paling penting dalam kendali operasional untuk proses-proses pirolisis.

Gambar 3 menunjukkan grafik kenaikan temperature dinding dan biomassa, dapat digambarkan bahwa laju pemanasan akan cenderung naik secara bertahap sesuai dengan pertambahan temperatur. Temperatur ini selanjutnya cenderung stabil 
karena pengaturan temperatur sesuai dengan kondisi operasional slow pirolysis.

Dengan sampel uji yang sama serta spesifikasi pemanas yang sama menghasilkan hasil yang berbeda antara pengujian pirolisis pada dua tipe yang berbeda yaitu tipe rotary dan fixed bed. Data laju pirolisis Rotary Kiln disesuaikan dengan penelitian laju pirolisis serbuk mahoni tipe fixed bed pada Majedi, et al., 2015.

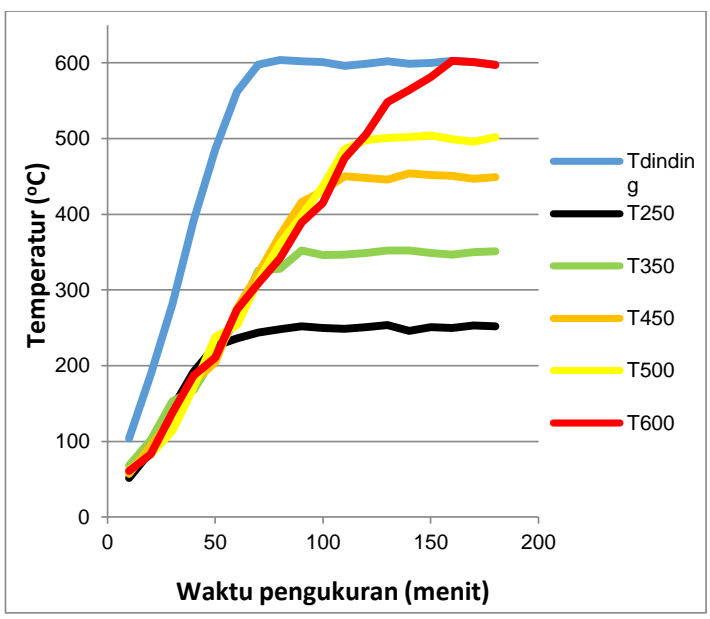

Gambar 3. Grafik temperatur dinding dan biomassa pada pirolisis Rotary Kiln

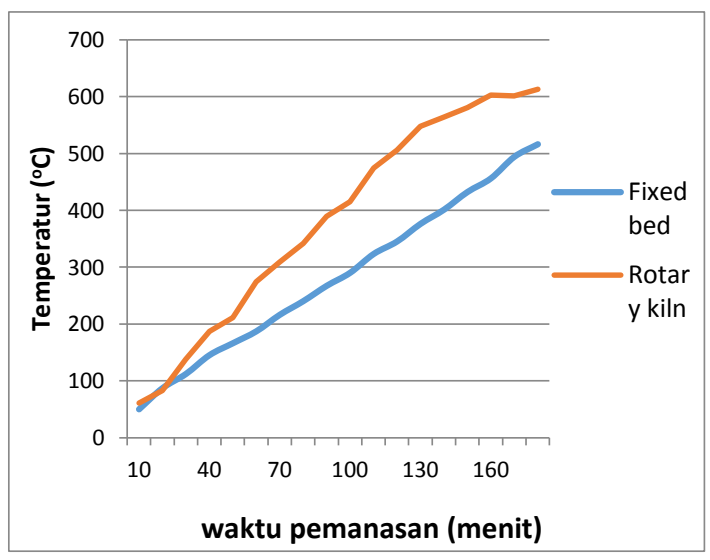

Gambar 4. Perbedaan laju pirolisis tipe Fixed Pirolisis dan Rotary Kiln pada variasi temperatur $600^{\circ} \mathrm{C}$.

Gambar 4 menunjukkan perbedaan laju pirolisis yang signifikan antara dua tipe pirolisis yang berbeda yaitu pada tungku diam (fixed) dan yang berputar (rotary). Perbedaan cukup signifikan ditunjukkan pada proses awal sampai akhir sepanjang 180 menit waktu penelitian dilakukan. Laju pirolisis pada Rotary Kiln mampu mencapai suhu optimum sebesar $600^{\circ} \mathrm{C}$ dengan waktu 150 menit yang selanjutnya temperatur ditahan sampai akhir proses, sedangkan pada type tungku diam (fixed) hanya menunjukkan suhu $432^{\circ} \mathrm{C}$ pada waktu yang sama.

Gradien temperatur dinding dan temperatur biomassa akan mempengaruhi proses pirolisis yang terjadi dalam tabung Rotary Kiln. Pada saat biomassa dipanaskan, beberapa komponen secara kimia menjadi tidak stabil dan terdegradasi secara termal atau diuapkan.

Laju aliran material bahan baku dan aliran gas pemanas serta kontrol temperatur reactor menjadi parameter-parameter kunci dalam laju pemanasan, temperatur puncak, waktu sisa dari padatan dan waktu kontak antara padatan dan gas pemanas. Faktorfaktor ini mempengaruhi distribusi produk dan propertinya [11].

\section{Kehilangan Massa}

Gambar 5 menunjukkan bahwa prosentase kehilangan massa cenderung bertambah sesuai dengan penambahan temperatur pemanasan. Prosentase kehilangan massa minimum terjadi pada variasi temperatur pemanasan $250^{\circ} \mathrm{C}$ yaitu sebesar 64,90\%. Prosentase kehilangan massa maksimum terjadi pada variasi temperatur pemanasan $600^{\circ} \mathrm{C}$ yaitu sebesar $84,57 \%$

Faktor kehilangan massa ini disebabkan akibat proses pemanasan bahan sehingga terjadi proses penguapan kandungan air biomassa. Selain itu, temperatur pirolisis juga menyebabkan proses pelepasan gas dalam biomassa. Proses-proses ini menyebabkan biomassa kehilangan sebagian massanya. 


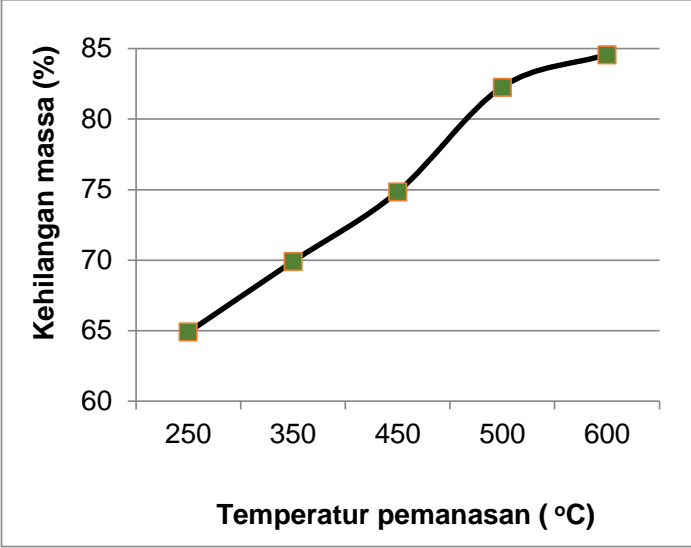

Gambar 5. Grafik hubungan temperatur dan prosentase kehilangan massa

Proses kehilangan massa ini sesuai dengan teori dalam slow pirolysis. Produkproduk non-combustible seperti $\mathrm{CO}_{2}$, senyawa organik, dan uap air, dihilangkan pada temperatur antara $100^{\circ} \mathrm{C}$ dan $200^{\circ} \mathrm{C}$. Di atas temperatur $200^{\circ} \mathrm{C}$, terjadi pemecahan struktur komponen bahan organik menjadi gas dengan massa molekul yang rendah. Proses ini selanjutnya akan menyisakan bahan dalam bentuk Char sehingga massa awal biomassa berkurang menjadi massa Char.

Hasil penelitian ini menunjukkan kesesuaian dengan hasil penelitian Paulauskas, et al [12]. Hal ini disebabkan karena temperatur yang lebih tinggi menyebabkan proses penguapan menjadi lebih besar. Proses ini selanjutnya akan menyebabkan massa akhir biomassa cenderung kecil sehingga kehilangan massa menjadi besar.

\section{Nilai Kalor}

Hasil penelitian menunjuk-kan bahwa nilai energi yang dihasilkan cenderung naik sesuai dengan penambahan temperatur pirolisis. Hasil penelitian menunjukkan kesesuaian dengan hasil penelitian Zajec [13]. Dimana dengan kenaikan temperatur dan pengaturan aliran partikel biomassa maka semakin banyak ikatan baik antar atom $\mathrm{C}$ maupun atom $\mathrm{C}$ dengan $\mathrm{H}, \mathrm{O}$ yang terputus maka kadar C (arang) semakin murni maka nilai kalor juga semakin tinggi.

Gambar 6 menunjukkan bahwa nilai kalor Char cenderung bertambah sesuai dengan penambahan temperatur. Nilai kalor Char minimum terjadi pada suhu $250^{\circ} \mathrm{C}$ yaitu sebesar 5763,941 kJ/kg. Nilai kalor maksimum terjadi pada suhu $600{ }^{\circ} \mathrm{C}$ yaitu sebesar $7592,524 \mathrm{~kJ} / \mathrm{kg}$.

Pirolisis merupakan proses dekomposisi thermokimia yang sangat kompleks karena dapat dipengaruhi oleh banyak faktor. Faktorfaktor ini meliputi bahan baku biomassa, metode pirolisis, peralatan yang digunakan dan kondisi operasinya. Temperatur pemanasan biomassa dengan Rotary Kiln yang digunakan sebagai variabel dalam penelitian ini berpengaruh terhadap perubahan volume dan massa serbuk kayu mahoni.

Perubahan volume dan massa serbuk kayu mahoni dalam bentuk Char selanjutnya akan berpengaruh terhadap faktor-faktor yang lain yang menjadi bahan analisa data. Faktor-faktor ini antara lain adalah nilai kalor, kehilangan massa, dan energy yang dihasilkan.

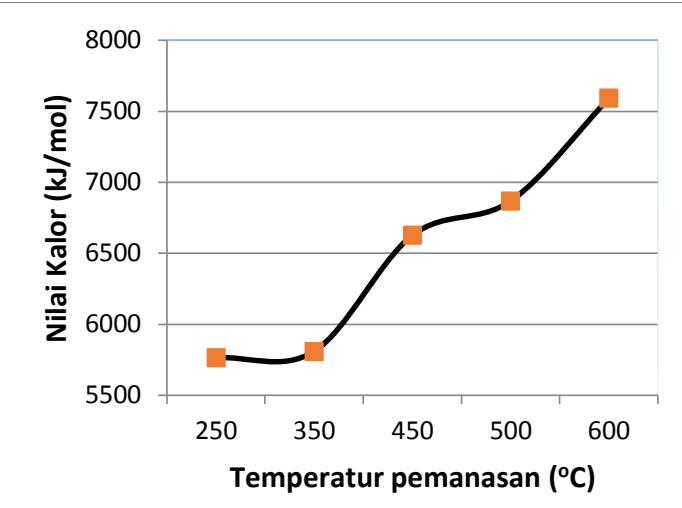

Gambar 6. Grafik hubungan temperatur dan nilai kalor Char

\section{KESIMPULAN}

1. Variasi temperatur berpengaruh terhadap Char hasil pirolisis serbuk kayu mahoni (switenia macrophylla) pada Rotary Kiln.

2. Kehilangan massa Char cenderung bertambah sesuai dengan penambahan temperatur pirolisis.

3. Nilai kalor Char cenderung bertambah sesuai dengan kenaikan temperatur. 


\section{DAFTAR PUSTAKA}

[1] Muhdhor RH, Wijayanti W, Anam K. 2013. Pengaruh Temperatur Pirolisis Terhadap Kualitas Dan Kinetic Rate Char Hasil Pirolisis Serbuk Kayu Mahoni. Jurnal Jurusan Teknik Mesin, Fakultas Teknik, Universitas Brawijaya.

[2] Zanzi R, Bai X, Capdevila P, Björnbom E., 2001, Pyrolysis Of Biomass In Presence Of Steam For Production Of Activated Carbon, Liquid And Gaseous Fuels, The $6^{\text {th }}$ World Congress Of Chemical Engineering

[3] Karlinasari L, Baihaqi $H$, Maddu A, Mardikanto TR, 2012, The Acoustical Properties of Indonesian Hardwood Species, Makara Journal of Science Vol 16 No 2: pp. 110-114

[4] Sukardayati, Dulsalam dan Osly Rachman, 2005, Potensi Dan Biaya Pemungutan Limbah Penebangan Kayu Mangium Sebagai Bahan Baku Serpih

[5] Ngadianto A, Widyorini L, Lukmandaru G, 2012 Ketahanan Papan Partikel Limbah Kayu Mahoni Dan Sengon Dengan Perlakuan Pengawetan Asap Cair Terhadap Serangan Rayap Kayu Kering Cryptotermes Cynocephalus Light, PROSIDING SEMINAR NASIONAL Masyarakat Peneliti Kayu Indonesia (MAPEKI) XIV: pp. 213-219

[6] Jamilatun S, Shakti DK, Ferdiant F, 2010, Pembuatan Biocoal Sebagai Bahan Bakar Alternatif dari Batubara dengan Campuran Arang Serbuk Gergaji Kayu Jati, Glugu dan Sekam Padi, Prosiding Seminar Nasional Teknik Kimia "Kejuangan Pengembangan Teknologi Kimia untuk Pengolahan Sumber Daya Alam Indonesia Yogyakarta" : ISSN 1693 -4393: pp. DO4 1-6
[7] Fatimah, Is. 2004. Pengaruh Laju Pemanasan Terhadap Komposisi Biofuel Hasil Pirolisis Serbuk Kayu. Jurnal Logika, Vol 1, No. 1

[8] Sunardjo, Sajima. 2012. Optimasi Kondisi Operasi Peleburan Konsentrat Zirkon Menggunakan Rotary Kiln. Heat Mass Transfer. DOI 10.1007/s00231-0110764-1. Springer-Verlag

[9] Carrasco JC, Oporto GS, Zondlo J, Wang J, 2014, Observed Kinetics Parameters During the Torrefaction of Red Oak (Quercus Rubra) in a Pilot Rotary Kiln Reactor, BioResources Vol 9 No 3: pp. 5417-5437

[10]Boateng AA, 2008, Rotary Kilns Transport Phenomena and Transport Processes, USA Elsevier Ltd.

[11]Brownsort PA, 2009, Biomass Pyrolysis Processes : Performance Parameters And Their Influence On BioChar System Benefits, A dissertation presented for the degree of Master of Science University of Edinburgh

[12] Paulauskas R, Džiugys $A$, Striūgas $N$, Garšvinskaitè L, Misiulis E, 2014, Experimental And Theoretical Investigation Of Wood Pellet Shrinkage During Pyrolysis, Energetika. T. 60. Nr. 1. P. $1-11$

[13]Zajec L, 2009, Slow Pyrolysis In A Rotary Kiln Reactor: Optimization And Experiments, Tesis, School for Renewable Energy Science, Akureyri, Icelan 